\title{
A Note on Growth, Welfare and Public Policy*
}

\author{
Uma nota sobre crescimento, bem-estar e politicas públicas
}

RESUMO: Nesta nota, os efeitos de crescimento e bem-estar das políticas fiscais e monetárias são investigados em quatro economias em que o investimento público faz parte do processo produtivo. É demonstrado que o crescimento é maximizado em níveis positivos de imposto de renda e inflação, mas que não há relação direta entre tamanho do governo, produtividade e crescimento ou entre inflação e crescimento. No entanto, a menos que não haja transferências, conflitos políticos ou bens públicos na economia, a maximização do crescimento não implica a maximização do bem-estar e a taxa tributária ideal e o tamanho do governo são maiores do que aqueles que maximizam o crescimento. O dinheiro não é superneutro e a taxa ideal de criação de dinheiro está abaixo da taxa maximizada de crescimento.

PALAVRAS-CHAVE: Gasto público; investimento; crescimento econômico.

ABSTRACT: In this note the growth and welfare effects of fiscal and monetary policies are investigated in four economies where public investment is part of the productive process. It is shown that growth is maximized at positive levels of income tax and inflation but that there is no direct relationship between government size, productivity and growth or between inflation and growth. However, unless there are no transfers, no political conflict or public goods in the economy, maximization of growth does not imply welfare maximization and the optimal tax rate and government size are greater than those that maximize growth. Money is not superneutral and the optimal rate of money creation is below the maximizing rate of growth. KEYWORDS: Public expenditure; investment; economic growth.

JEL Classification: O41; H30.

\section{INTRODUCTION}

This note investigates the effect of changes in the composition, level and financing of government expenditures on economic growth. We basically present some main results of the literature while also adding different types of public outlays.

\footnotetext{
* We gratefully acknowledge the comments of Alex Galetovic, Flavio Ataliba Barreto, Roberto Ellery Jr. We also thank CNPq and Pronex for financial support.

* Escola de Pós-Graduação em Economia, Fundação Getúlio Vargas, Rio de Janeiro/RJ, Brasil. E-mail: Pedro.ferreira@fgv.br. Orcid: https://orcid.org/0000-0001-9560-8200.
} 
Emphasis is given to the effect of alternative forms of government financing on growth and welfare when public-sector investment affects private returns and productivity. We start working with an "AK" technology dueto Rebelo (1991) expanded by the presence of public investments, following Barro (1990), Barro and Sala-iMartin (1992 and 1995), among others. We will subsequently introduce more structure to this basic model, first adding a public good that directly affects individuais' utility. The next model divides agents in two classes, capitalists who own the capital and save, and workers who do not save and live out of wage income. Here we follow Alesina and Rodrik (1992) closely. In the last model money is introduced.

We assume in all these models that government expenditures are divided in two parts: one "productive" (R\&D, education, capital formation, infrastructure etc.) which affects the productivity of the private-sector technologies while the other, "consumption", does not and will be modeled either as consumption transfers to the private sector, a public good or simply as "waste". In these economies, government expenditures are financed through distortionary taxation and/or seignorage.

We aim to use these different structures to answer two basic questions. We first want to investigate the impact on economic growth of shifts of public expenditures from investment to consumption. Or more generally, we want to know what the macroeconomic effects of changes in fiscal and monetary policy are when the productive role of government is taken into account.

The second objective of this note is to study the optimal level of taxes and other policy instruments in economies where public investment is part of the production function. By optimal we mean chosen by a benevolent government that takes individuais' action as given. Our aim is to compare the optimal tax rate, the optimal public investment ratio and the optimal rate of money creation with those that maximize growth.

The four different frameworks we use give different answers to these questions. The answer depends both on the way the public sector finances its expenditures and the particular form that these expenditures assume. ln general, growth is maximized when public consumption or transfers are zero and at positive levels of tax and inflation. Moreover, there is an interval where growth rates increase with the tax rates. Zero taxation is not an equilibrium as tax revenues are needed for the financing of public infrastructure.

But maximum growth does not imply optimal growth. Unless public transfers are wasted and do not affect people's behavior in any way, the optimal tax rate is always above the maximum growth rate and the optimal ratio of investment to total public expenditures is below one, the ratio that maximizes growth. On the other hand, the optimal rate of money supply is positive in all economies, but always below the rate that maximizes growth.

Although these models are all highly abstract, we can gain some insights about the role of government in certain recent growth experiences. For instance: public expenditures in capital, for a given level of total expenditures and taxes, positively affect growth rates because this increases the productivity of physical capital. On the other hand, growth rates would fall with taxes for a given level of public investment 
as this reduces the return on private investment, so that there is no direct relationship between government size, productivity and economic growth. A large government with relatively large unproductive expenses would give rise to the usual intuition of the effects of big government over the economy (lower productivity and lower growth) but this may not be true if the proportion of productive expenditures on total expenditures is high. Moreover, depending on the value of the output elasticity to public capital and other relevant parameters, big government may be optimal. Therefore, the usual IMF recipe for troubled countries may well misfire if the cuts in government size are dane in the wrong sectors or in the wrong proportions.

When money is introduced in this economy, the expenditure size of government remains the same but now we have one extra source of distortion. It is still true that increases in the public investment ratio would probably increase growth, so that two countries with the same rate of inflation but different proportions of public capital could have different rates of growth. In other words, there is no oneto-one relationship between inflation and growth. Nevertheless, if the level of investments remains constant while inflation rises, the increase in the total government expenditure financed by the extra inflation-tax revenue will be accompanied by lower rates of growth. It may be true, however, that for some combination of parameters an increase in seignorage can lead to faster growth. In this case, the distortionary effect of higher inflation is offset by the effects of public investment on the marginal productivity of capital.

The model with money could help the understanding of the recent experience of some Latin America nations. During the fifties and sixties, countries in this region experienced fast economic growth (average rates sometimes higher than $4 \%$ ), while government investment increased sharply. At the same time, inflation rates were well above the acceptable level for developed countries (in Brazil it was seidom below $15 \%)$. So we can think of this set-up as a large public sector with high investment ratio and high money creation with a combination of parameters that allows the effect of public investment on growth to exceed the negative effect from higher taxes and seignorage. However, especially after the Mexico crisis in 1982, we observe an acceleration of inflation and a reduction of expenditures in infrastructure. At the same time, expenditures in consumption rise due to political pressures. In this case, both the rate and the level of public investment fell, while distortionary taxation increased. Both factors could help to explain the sharp reduction in growth rates experienced by these countries during the eighties.

The paper is organized as follows: in the next section the basic framework is presented, in section three public good is introduced, in section four a model with two classes is presented and in section five money is introduced to the basic model. Finally, in section six some concluding remarks are made.

\section{THE BASIC MODEL}

The simplest model that generates endogenous growth is the so-called "AK model", which we will use it as a first step toward a more comprehensive model. Note, however, that our technology includes government expenditures. 
Let the technology be given by

(1) $y_{t}=A\left(g_{i}\right)^{\phi} k_{t}=A(\lambda g)^{\phi} k_{t}$

ln the above expression $g$ is the ratio of government expenses $(G)$ to output, $\mathrm{g}_{\mathrm{i}}$ the ratio of public investment to output, $\phi$ is a positive parameter smaller than one that gives the productivity of government capital and $\lambda$ is the proportion of investments to total public expenditures. As is usual in this type of model, $\mathrm{K}$, should be interpreted in a broad sense to include, for instance, human capital. Government expenditures are financed by a proportional tax on income.

We also make the usual assumption that the instantaneous utility function is CES and we rule out population growth. The consumer problem is

$$
\begin{aligned}
\max _{\{c,\rangle} & \int_{0}^{\infty} \frac{C_{t}^{1-\sigma}-1}{1-\sigma} \mathrm{e}^{-\rho t} d t \\
& \text { s.t. } \quad \dot{k}=(1-\tau) y_{(\mathrm{t})}-c_{(\mathrm{t})}-\delta k_{(\mathrm{t})}+v_{(\mathrm{t})}
\end{aligned}
$$

lnthe above expression 8 is the depreciation rate of capital, $v$ government transfers $(=(1-\lambda) G), p$ is the discount rate and $\sigma$ is the inverse of the elasticity of substitution. The expression simply says that the net investment is equal to the difference between income $((1-\tau) y+v)$ and consumption. Alternatively we could suppose that government consumption is always wasted, so that $v_{(\mathrm{t})}$ would not be present in the above expression. This would not change the results.

The solution for this problem is given by the usual first order conditions (from this point on we drop the time subscript for the sake of simplicity)

(2) $c^{-\sigma}=\varphi Z$

$$
\varphi=\varphi(\rho-r+\delta)
$$

and the transversality condition:

$$
\lim _{t \rightarrow \infty} e^{r t} \varphi k_{t}=0
$$

In the above expressions $r$, the interest rate, is given in equilibrium after the solution of the problem of the firms, by $(1-\tau) A(\lambda g)^{\phi}$. From equations two and three we obtain the growth rate of consumption, $\gamma$ :

$$
\gamma=(r-\delta-\rho) / \sigma
$$

From the above result and the transversality condition it can be shown that capital grows at the same rate as consumption. Given that by expression one output grows at the same rate as capital, and consequently also $G$ (which is equal to $\tau \mathrm{y}$ ), all the variables of this economy are in a balanced growth path at the same rate $y$. From the expression for $r$ we have:

(4) $\gamma=\left((1-\tau) A\left(g_{i}\right)^{\phi}-\delta-\rho\right) / \sigma=\left((1-\tau) A(\lambda g)^{\phi}-\delta-\rho\right) / \sigma$ 
so that for a given tax rate ' $t$ an increase in the parameter $\lambda$ (a rise in the government investment ratio) with $g$ constant will boost the rate of growth of this economy by

$$
\frac{d \gamma}{d \lambda}=\frac{d \frac{(1-\tau) A\left(g_{c}\right)^{\phi}}{\sigma}}{d \lambda}=\frac{(1-\tau) A \phi g^{\phi}}{\sigma \lambda^{1-\phi}}
$$

which is always positive for any $\lambda$ between zero and one. Consequently, $\lambda$ equal to one maximizes growth. But note also that if a change in the composition of public expenditures in favor of investment helps economic growth, the impact decreases with the size of $\lambda$. The diminishing returns of $\lambda$ results, of course, from our hypothesis that $\phi$ is less than one. We will see soon that there is robust empirical evidence that this is in fact the case.

On the other hand, it is not dear that growth rates will fall with taxation as in Rebelo (1991), among others. In those models the interest rate would be given by $(1-\tau) A / \sigma$ " and the marginal productivity of capital is not affected by public investment. But in the present case, as in Barro (1991) and Barro and Sala-i-Martin (1991), this is no longer true. The interest rate is given by $(1-\tau) A(\lambda g)^{\phi}$ so that the negative impact of higher tax rates may be compensated by the positive effect brought about by the increase in public investments. Note that:

$$
d \gamma=\frac{1}{\sigma}\left[-A(\lambda g)^{\phi} d \tau+\phi(1-\tau) A(\lambda g)^{\phi} g^{-1} d g\right]
$$

After some manipulations we obtain:

$$
\text { (6) } \frac{d \gamma}{d \tau}=\frac{A(\lambda g)^{\phi}}{\sigma}\left[\frac{1-\tau}{\tau} \phi \eta_{g \tau}-1\right]
$$

where $\eta_{\mathrm{g} \tau}$, is the elasticity of government expenditures with respect to taxes. From the above expressions, $\mathrm{d} \gamma / \mathrm{d} \tau$ is positive only if $\eta_{\phi \tau} \phi>\tau /(1-\tau)$, and negative otherwise. For the general case where $g$ is not proportional to income and in the hypothesis that there is a "nice" Laffer curve in this economy (as is the case for this simple model), the effect of taxes on growth would depend on the level of the tax rate, the productivity parameter of public capital $\phi$ and the position of $g$ in the Laffer curve. If the economy is in the left side of the Laffer curve and not close to the peak, $\eta_{\phi \tau}$ is not only positive but relatively large, so that it is possible that the first term in the brackets of the above expression is larger than one. ln this case higher rates will increase rather than decrease growth. The intuition is obvious: the negative distortionary effect of higher tax rates is smaller than the positive effect of the increase in public capital on the marginal productivity of private capital. A "big government", however, which means $g$ close or to the right of the maximum of the Laffer curve, can only harm growth with higher taxes.

In the unrefined framework of our model, as we did not allow public debt and/ or money, this general discussion can be considerably simplified. Here the variable $g$, which is $G / y$ by definition, is given by $\tau y / y$ which reduces, of course, to $\tau$. $\ln$ this 
case, the elasticity of $g$ with respect to $\tau$ is constant and equal to one. Now the condition for the growth rate to increase with tax rates is just:

$$
\tau<\frac{\phi}{(1-\phi)}
$$

With the estimates of $\phi$ available in the literature, we can estimate the tax rate interval for which the derivative of $\gamma$ with respect to $\tau$ is positive. These estimates, for American aggregate data, vary considerably. For instance, Aschauer (1989) found values around 0.35 while in Cavalcanti Ferreira (1993) they are 0.09 on average and in Nadiri and Manuneas (1992) the estimates all lie between these two values. $\ln$ the first case $d \gamma / d \tau$ is positive while the tax rate (which is equivalent to the tax burden in the model) remains below 0.25, a value close to the Brazilian and American tax burden. However, for $\phi$ close to 0.1 , this derivative becomes negative for $\tau$ above 1/11, so that the tax burden that maximizes growth is well below that observed in capitalist economies. For $\phi$ close to zero, we obtain the usual neoclassical result that tax increases can never boost economic growth. But the main conclusion of this section remains that, once we recognize the productive role of the government, $d \gamma / d \tau$ negative is no longer a general result. This, of course, is not a new result, it is present in Barro (1991) and many other studies. Our main objective, however, is to compare the fiscal policy that maximizes growth with the fiscal policy that maximizes the individual's utility, as analyzed in the next section.

\section{The Government Problem}

We can now investigate what the optimal tax rate and $\lambda$ would be if chosen by a government that wants to maximize agents' welfare. We will use the simplifying assumption that the transfers $\mathrm{V}$ are zero in every period (they are simply wasted). Notice that from the equilibrium growth rate we have:

$$
\dot{k}=\frac{\left((1-\tau) A(\lambda \tau)^{\phi}-\delta-\rho\right)}{\sigma} k=\frac{(r(\lambda, \tau)-\delta-\rho)}{\sigma} k
$$

From the consumer's problem we have:

$$
\dot{k}=(r-\delta) k-c
$$

Manipulating these two equations above we obtain an expression for consumption:

(7) $c=((r(\lambda, \tau)-\delta)(1-1 / \sigma)+\rho / \sigma) k$

Expression seven says that consumption in equilibrium is a fixed proportion of capital if it is recognized that the interest rate for given $\tau$ and $\lambda$ is constant. Moreover, if instead of the more general CES we had a logarithm utility function, so that $\sigma$ is equal to one, expression seven would be simply $c=\rho k$. This gives us the usual "Calvinist" vision of growth: a thriftier nation which gives a high weight to the future (low $\rho$ ) would consume less today but grow faster and consume more in the future. 
Using expression seven above, the government problem is:

$$
\max _{\langle\lambda, \tau|} \int_{0}^{\infty}\left(\frac{((r(\lambda, \tau)-\delta)(1-1 / \sigma)+k)^{1-\sigma}-1}{1-\sigma}\right) \mathrm{e}^{-\rho t} d t
$$

$$
\text { s.t. } \dot{k}=\gamma(\lambda, \tau) k
$$

The Hamiltonian of this problem is given by:

$$
H(\lambda, \tau)=\frac{(((r(\lambda, \tau)-\delta)(1-1 / \sigma)+\rho / \sigma) k)^{1-\sigma}-1}{1-\sigma}+\theta \gamma(\lambda, \tau) k
$$

Taking derivatives with respect to $\tau$ and $\lambda$, we obtain:

$$
\text { (8) } c^{-\sigma}(1-1 / \sigma) k \frac{\partial r}{\partial \tau}+\theta k \frac{\partial \gamma}{\partial \tau}=0
$$

$$
\text { (9) } c^{-\sigma}(1-1 / \sigma) k \frac{\partial r}{\partial \lambda}+\theta k \frac{\partial \gamma}{\partial \lambda} \geq 0
$$

Taking into account (from expression four) that the derivative of the interest rate with respect to $\tau$ and $\lambda$ is equal to $\sigma$ times the derivative of the growth rate with respect to the same variables, equations eight and nine reduce to:

$$
\begin{aligned}
& \left(c^{-\sigma}(1-1 / \sigma) \sigma+\theta\right) \frac{\partial \gamma}{\partial \tau}=0 \\
& \left(c^{-\sigma}(1-1 / \sigma) \sigma+\theta\right) \frac{\partial \gamma}{\partial \lambda} \geq 0
\end{aligned}
$$

The left hand side of expression 11 is only zero when $\mathrm{d} \gamma / \mathrm{d} \tau$ is zero, as the term in brackets is positive for the vast majority of estimates of the parameter $\sigma$. Hence, for this particular economy the optimal tax rate is the tax rate that maximizes growth. A government that aims to maximize the welfare of its citizens should pick a policy that maximizes the growth of the economy: choose $\tau^{*}$ equal to $\phi /(1+\phi)$. As for the investment ratio, the result is the same, pick lambda equal one which is the comer solution for growth maximization. Both these results are somehow expected but they are by no means general. If the transfers are not zero or if, as we will see next, there are public goods that affect people's utility, the optimal policy will no longer be growth maximization.

\section{A MODEL WITH PUBLIC GOODS}

The present model is similar to the previous one in everything except the presence of a public good, financed by a proportion $(1-\lambda)$ of tax revenues, in the instantaneous utility function: 


$$
u\left(c_{t}, v_{t}\right)=\frac{c_{t}^{1-\sigma}-1}{1-\sigma} v_{t}^{\alpha}
$$

In the expression above $v_{t}$ is given by $(1-\lambda) g=(1-\lambda)^{~} \mathrm{t}$, as $\mathrm{g}$ is given by $\mathrm{G} / \mathrm{y}$ and $G$ is simply $\tau$ times the income. We are implicitly assuming that the consumption of public goods is subject to some form of congestion, so that it is its proportion to income rather than its absolute supply that affects the consumer's utility. Moreover, with this hypothesis, $\mathrm{v}_{\mathrm{t}}$ constant for given $\lambda$ and $\tau$.

The consumer solves the same problem as in the last section, using the now amplified utility function and noting that there are no transfers. The technology is the same, with a proportion $\lambda$ of government expenditures going to public investment, which is an argument of the production function. Government finances its expenses by taxing income with a tax rate of $\tau$.

The first order conditions of the representative consumer's problem with respect to consumption and capital are given, respectively, by

$$
\begin{aligned}
& c_{t}^{-\sigma} v^{\alpha}=\varphi \\
& \dot{\varphi}=\varphi(\rho-r+\delta)
\end{aligned}
$$

Note that vis constant, so that the growth rate of consumption in equilibrium is still given by

$$
\gamma=\left((1-\tau) A(\lambda \tau)^{\phi}-\delta-\rho\right) / \sigma
$$

and it is straightforward to show that capital, income and public expenses all grow at this same rate. Given the way public goods were introduced in the utility function - and this is one of the only two ways compatible with a balanced growth path in "AK" models (the other one being the logarithm utility function) — the growth rate has exactly the same format in the previous model without public goods. Consequently, it is still the case that the growth rate grows with $\tau$ for tax rates below $\phi /(1+\phi)$ and always grows with $\lambda$, so that growth is maximized at

$$
\tau=\tau^{*}=\frac{\phi}{1+\phi}, \text { and } \lambda=\lambda^{*}=1
$$

\section{The Government Problem}

The government problem is no longer the same. Now the growth effect of extra investments must be weighted against the utility gain of additional public goods. It is still the case that the consumption decision rule is given by

$$
\mathcal{c}=((r(\lambda, \tau)-\delta)(1-1 / \sigma)+\rho / \sigma) k
$$


so that the problem is now

$$
\max _{\{\lambda, \tau\}} \int_{0}^{\infty}\left(\frac{(((r(\lambda, \tau)-\delta)(1-1 / \sigma)+\rho / \sigma) k)^{1-\sigma}-1}{1-\sigma}((1-\lambda) \tau)^{\alpha}\right) \mathrm{e}^{-\rho t} d t
$$

$$
\text { s.t. } \dot{k}=\gamma(\lambda, \tau) k
$$

The only difference with respect to the previous case is the presence of the term $((1-\AA) r)^{a}$ in the utility function. The first order conditions with respect to 1: and À are now, respectively,

$$
\begin{aligned}
& c^{-\sigma}(1-1 / \sigma) k((1-\lambda) \tau)^{\alpha} \frac{\partial r}{\partial \tau}+\theta k \frac{\partial \gamma}{\partial \tau}+\frac{\alpha U\left(c_{t}, v\right)}{v} \frac{\partial v}{\partial \tau}=0 \\
& c^{-\sigma}(1-1 / \sigma) k((1-\lambda) \tau)^{\alpha} \frac{\partial r}{\partial \lambda}+\theta k \frac{\partial \gamma}{\partial \lambda}+\frac{\alpha U\left(c_{t}, v\right)}{v} \frac{\partial v}{\partial \lambda}=0
\end{aligned}
$$

Expression 14, after some simplifications, reduces to

$$
\left(c^{-\sigma}(\sigma-1) v^{\alpha}+\theta\right) k \frac{\partial \gamma}{\partial \tau}+\frac{\alpha U\left(c_{t}, v\right)}{\tau}=0
$$

Note that $\tau=\tau^{*}$, the tax rate that maximizes growth, is no longer the optimal policy. This would only be the case if the last term on the left hand side was zero, which corresponds to the previous model without public goods. Now, in order for the whole expression to be zero, $\partial \gamma l \partial \tau$ rcannot be zero any longer. Moreover, given that the term in brackets in the first expression on the left hand side is positive like the second expression, it turns out that $\partial \gamma l \partial \tau$ has to be negative in order for the whole expression to be zero. But we know that this derivative is only negative for tax rates greater than $\tau^{*}$, sothat in this case the optimal policy requires a tax rate greater than the one that maximizes growth.

This result is similar to results obtained by Alesina and Rodrik (1992), where growth maximization is also not optimal. The intuition for it is the following: at $\tau$ equal to $\tau^{*}$, thefirst order effect of an increase in the tax rate on growth is zero, as this is the rate that maximizes growth, so there is only a second order effect. However, there is a first order effect on public goods: as the tax rate deviates from $\tau^{*}$, the government can increase welfare by financing extra public goods. Hence, there is an incentive for the government to deviate from $\tau^{*}$ and operate at tax rates higher than that.

It is interesting to note that, as we saw in the last section, government in general operates at tax rates (in the models of sections two and three: at government sizes) that are well above those that maximize growth. One possible explanation advanced by the present model is the fact that they operate with multiple tasks and objectives and that at least part of their actions affect the utility of agents. This fact, as we have just seen, implies that the optimal tax rates or government sizes are 
above $\tau^{*}$. Of course, the environment in which governments choose their policies is much richer than ours, but the lesson from this section remains true: it is not necessarily bad that government policies do not maximize economic growth, for this may be an answer to the demands of the citizens.

Expression 15, after some manipulations becomes

$$
\left(c^{-\sigma}(\sigma-1) v^{\alpha}+\theta\right) k \frac{\partial \gamma}{\partial \lambda}+\frac{\alpha U\left(c_{t}, v\right)}{(1-\lambda)}=0
$$

From 16 and 17 we obtain:

$$
\frac{\gamma_{t}}{\gamma_{\lambda}}=-\frac{(1-\lambda)}{\tau}
$$

which after some manipulations becomes:

$$
\frac{(1-\lambda)}{\tau} \frac{(1-\tau)}{\lambda}=\left(\frac{(1-\tau)}{\tau} \phi-1\right)
$$

Lambda equal to one in expression 16 is only a solution when the right hand side is zero, which corresponds to the case when $\tau$ is equal to $\tau=\phi /(1+\phi)$, the tax rate that maximizes growth. But the optimal rate $t$ is greater than $\tau^{*}$, so that $\AA$ is always less than one. This makes economic sense, as lambda equal to one implies zero public goods in this model. Consequently, any increase in $\lambda$ would increase the consumers' welfare, because the utility level is zero with zero public goods.

\section{A MODEL WITH TWO CLASSES}

In this section we follow Alesina and Rodrik (1992 and 1994) closely. Let the technology be given by:

$$
Y_{t}=A K_{t}^{\alpha} G_{t}^{1-\alpha} L_{t}^{1-\alpha}
$$

where $\mathrm{L}$ is labor and $\mathrm{G}$ is public investment in infrastructure. Government finances its expenses only with a tax over capital stock, and a proportion $\lambda$ of the revenues goes to public investment, so that $\mathrm{G}$ is given by $\lambda . \tau \mathrm{K}$, and $(1-\lambda)$ of the revenues are transferred to workers.

There are two classes in this economy. Capitalists live from capital income and are the only class that saves. Workers do not save and live from wage income and government transfers $v$, which are equal to $(1-\lambda) \tau K .^{1}$ The utility function of both

\footnotetext{
1 The model could be written such that people would have income from both capital and wages, but with different proportions of income from each one of these sources, so that there would have distribution of capital and saving among the population. This would not change the basic conclusions we want to stress here. This path is investigated by Alesina and Rodrik (1994).
} 
classes is assumed to be logarithm. The problem of the representative capitalist is given by (letting $\mathrm{C}_{\mathrm{k}}$ represent his consumption level):

$$
\begin{aligned}
& \max _{\{c k,\}} \int_{0}^{\infty} \ln C_{k} e^{-\rho t} d t \\
& \quad \text { s.t. } \dot{K}=(r-\tau) K-C_{k}
\end{aligned}
$$

It is straightforward to show, from the first order conditions of this problem, that the rate of growth of $\mathrm{Ck}$, $\mathrm{y}$, is given by $(r-\tau-\rho)$.

The problem of the representative worker is:

$$
\begin{aligned}
\max _{\left(c_{L}\right)} \int_{0}^{\infty} \ln C_{L} e^{-\rho t} d t \\
\text { s.t. } C_{L}=w L+v
\end{aligned}
$$

As already stressed, the representative worker do not save but consumes the equivalent of his income in every period, which is equal to his wage income plus government transfers. Notice that workers and capitalists are assumed to have the same discount rate. This is not necessary for the results, it only simplifies the algebra.

It can be shown, solving the consumer's problem and using the transversality condition of the capitalist's problem, that income, capital and the consumption of the representative worker all grow at the same rate y as the capitalist's consumption.

From the firms' problem we obtain the equilibrium wage and interest rate:

$$
\begin{aligned}
& r=\partial y / \partial K=\alpha A(\lambda \tau)^{1-\alpha} \equiv r(\lambda, \tau) \\
& w=\partial y / \partial L=(1-\alpha) A(\lambda \tau)^{1-\alpha} K \equiv \omega(\lambda, \tau) K
\end{aligned}
$$

Using expression for the interest rate, the growth rate can be written as:

$$
\gamma=\alpha A(\lambda \tau)^{1-\alpha}-\tau-\rho=\gamma(\lambda, \tau)
$$

The derivative of the growth rate with respect to lambda is always positive. Hence, as in the previous models, growth is maximized when the government expends all its money in investments and none in transfers, which in the present case goes entirely to the workers. On the other hand, from the derivative of y with respect to ' $t$ we obtain that growth is maximized when

$$
\tau=\tau^{*}=\left[\alpha(1-\alpha) A \lambda^{1-\alpha}\right]^{1 / \alpha}=[\alpha(1-\alpha) A]^{1 / \alpha}
$$

In the last expression in the right hand side we used the fact that $\lambda$ equal to one maximizes growth and we also normalized L to one without any loss of generality. From expression (17) it is possible to show that $\partial \gamma / \partial \tau$ is positive or negative either $\tau$ is greater or smaller than $[\alpha(1-\alpha) A]^{1 / \alpha}$. Hence, either tax increases will hurt or help economic growth depends on either the tax rate is already too high (above $\tau^{*}$ ) or still too low (below $\tau^{*}$ ). As in the two previous models the relationship between economic growth and taxation is not linear or monotone. The productive role of (part of) public expenditures may compensate the distortionary effect 
of taxes on saving decisions, and, consequently, increases in taxes may be followed by an acceleration of growth if tis less than $\tau^{*}$.

We will now solve the government's problem, assuming that it gives a weight $\beta$ to workers and $(1-\beta)$ to capitalists. The problem in this case is:

$$
\begin{aligned}
\max _{\{\lambda, \tau\}}(1-\mathrm{b}) \int_{0}^{\infty} \ln C_{k} e^{-\rho t} d t+\int_{0}^{\infty} \ln C_{L} e^{-\rho t} d t \\
\quad \text { s.t. } C_{k}=\rho K, C l=(\omega(\lambda, \tau)+(1-\lambda) \tau) K, \dot{K}=\gamma(\lambda, \tau) K
\end{aligned}
$$

The Hamiltonian of this problem is:

$$
H(K, \tau, \lambda)=(1-\beta) \ln \rho K+\beta \ln (\omega(\lambda, \tau)+(1-\lambda) \tau) K+\theta \gamma(\lambda, \tau) K
$$

Taking derivatives with respect to $\lambda$ and $\tau$ the following first order conditions were obtained:

$$
\begin{aligned}
& \text { (20) } \frac{\partial H}{\partial \tau}=\beta\left(\frac{\partial \omega(\lambda, \tau)}{\partial \tau}+(1-\lambda)\right) \frac{K}{C_{L}}+\theta \frac{\partial \gamma(\lambda, \tau)}{\partial \tau} K=0 \\
& \text { (21) } \frac{\partial H}{\partial \lambda}=\beta\left(\frac{\partial \omega(\lambda, \tau)}{\partial \lambda}-\tau\right) \frac{K}{C_{L}}+\theta \frac{\partial \gamma(\lambda, \tau)}{\partial \lambda} K=0
\end{aligned}
$$

From expression 20 it is clear that only when the government gives no weight to the welfare of the representative worker $(\beta=O)$, the optimal tax rate will be equal to $\tau^{*}$, the tax rate that maximizes growth. As long as beta is greater than zero, $\partial \gamma / \partial \tau$ is never zero in expression 20 and the growth rate is below the maximum. ln other words, maximization of growth is the best choice for the welfare of the representative capitalist but not for the representative worker, so that only a government of the capitalists would maximize growth. In an economy with distributive conflict, maximizing growth does not imply maximizing welfare.

Notice also that the term in brackets in the first expression in the right hand side of (20) is always positive. This will imply that $\partial \gamma / \partial \tau$ is negative and that the optimal tax rate is to the right of $\tau^{*}$, the growth maximizing level. The same result as in the model with public goods is obtained here. At $\tau^{*}$ both growth and capitalist welfare is maximized. Consequently, a marginal increase in $\tau$ from $\tau^{*}$ will have only a second-order effect on the welfare of capitalists but a first-order effect on the consumption of workers, so that workers are made better of and capitalists remain unhurt. So, as long as the government gives some weight to the welfare of workers, it will pick $\tau$ greater than $\tau^{*}$ and the growth rate will be below the maximum.

As opposed to the model with public goods and representative consumer, in this model it can be the case that optimal $\lambda$ is the same as the one that maximizes growth $(\lambda=1)$. This is true either $\beta$ is too small, so that the government do no care very much to the welfare of workers, or $\rho$ is very small. ln this last case workers do not discount heavily the future, so that they would rather sacrifice their level of consumption today (receiving less direct transfers) in order to have a higher rate of growth for all subsequent periods. But remember that tis always above its growth maximizing level, so that even if there is no direct transfer at all and only public investments, the growth rate will be below the maximum attainable level. 


\section{GROWTH AND MONEY}

In this section we introduce money in the model of section two, keeping the same technology with government investment as a separate argument of the production function. Following Sidrauski (1967), among others, money is an argument of the instantaneous utility function which is given by

$$
U\left(c_{t}, m_{t}\right)=\beta \ln m_{+}+(1-\beta) \ln c_{t}
$$

The consumer problem is now:

$$
\begin{aligned}
\max _{\left\{c_{t}\right\},\left(m_{i}\right\}} \int_{0}^{\infty}\left\langle\beta \ln m_{t}+(1-\beta) \ln c_{t}\right) e^{-\rho t} d t \\
\text { s.t. } a=r a_{(\tau)}-c_{(\tau)}-(\pi+r) m_{(\tau)}
\end{aligned}
$$

where $\mathrm{a}=\mathrm{k}+\mathrm{m}$ is the consumers' wealth, $\pi$ is the rate of inflation and the interest rate $\mathrm{r}$ is equal to $(1-\tau) A(\lambda g)^{\phi}$. We assume that government consumption is wasted rather than transferred to consumers.

The solution for the present problem is given by the following first order conditions:

$$
\begin{aligned}
& (1-\beta) c^{-1}=\varphi \\
& \beta m^{-1}=\varphi(\pi+r) \\
& \dot{\varphi}=\varphi(\rho-r)
\end{aligned}
$$

and appropriate transversality conditions. In the expressions above, $\mathrm{j}$ is the costate variable.

From equations 23 and 25 above, we obtain that the rate of growth of consumption is given by $\gamma=\mathrm{r}-\rho$. It is equivalent to the growth rate in the second section, as $\sigma$ is now equal to one. Also from equation 24 and 25 we obtain the rate of growth of money holdings, which is identical to the growth rate of consumption, so that we have:

$$
\gamma=\frac{c}{c}=\frac{\dot{m}}{m}=(r-\rho)
$$

Using the transversality condition for capital accumulation and the law of motion of the wealth variable, it is straightforward to show that capital and output grow at this same rate $\gamma$.

The derivative of $\mathrm{y}$ with respect to the tax rate is given by:

$$
\frac{d \gamma}{d \tau}=A(\lambda g)^{\phi}\left(\frac{1-\tau}{\tau} \phi \eta_{g \tau}-1\right)
$$

Equation twenty-six corresponds exactly to equation six of section two. Hence, the response of $\gamma$ to changes in the tax rates still depends on the relative size of $\phi, \tau$ and the elasticity of $\mathrm{g}$ with respect to tax. Note, however, that the elasticity is no 
longer constant and equal to one as $\mathrm{G}$ is now given by $\mathrm{G}=\tau \mathrm{y}+\mu \mathrm{m}$, and the total seignorage, $\mu \mathrm{m}$, changes when the tax rate changes. But it is still true that growth is maximized when $\tau=\eta_{\phi \tau} \phi /\left(1+\eta_{\phi \tau} \phi\right)$, but now $\eta_{\phi \tau}$, is no longer constant. It is also straightforward to show that lambda equal to one maximizes growth.

The derivative of the growth rate with respect to $\mu$ is given by:

$$
\frac{d \gamma}{d \mu}=A(\lambda g)^{\phi} \frac{(1-\tau)}{\mu} \phi \eta_{g \mu}
$$

The sign of expression 27 depends only on the elasticity of g with respect top being positive or negative, given that all the other terms are positive. Everything else being constant, as longas the receipt from money-creation grows with $\mu$, the common rate of growth of the economy rises with $\mu$. This result contrast with the superneutrality result from the traditional Sidrauski model, as we might expect when public expenditures, financed partly by seignorage, were introduced in the production function. When some functionality is given to public expenditures, we can see from expression 27 above that the growth rate of money supply affects the common growth rate of all real variables of the economy.

Note, however, that the maximization of growth does not necessary imply maximization of seignorage. Expression 24 is zero only when $\eta_{g \mu}$ is zero. But $\eta_{g \mu}$ is given by

$$
\eta_{g \mu}=\frac{\mu m}{g} \frac{1}{y}\left(1+\eta_{m \mu}-\eta_{y \mu}\right)
$$

where $11 m \mu$ is the elasticity of money balances with respect to $\mu$ and $17 y \mu$ is the income elasticity to $\mu$. Seignorage is maximized when $\eta_{m \mu}$ equals minus one, which is the usual Cagan condition. But growth is maximized when $\eta_{m \mu}$ equals minus one plus $\eta_{y \mu}$, or when the difference between these two elasticities equals minus one.

We can now derive the policy functions of the model, following Roubini and

Sala-i-Martin (1995). Note that from the first order condition for money and consumption we obtain

$$
m=\frac{c}{\pi+r} \frac{\beta}{1-\beta}=\frac{c}{\rho+\mu} \frac{\beta}{1-\beta}
$$

Substituting in the expression for capital we obtain

$$
k=\frac{c}{\rho}\left(1+\frac{\mu}{\rho+\mu} \frac{\beta}{1-\beta}\right)
$$

From this expression we can easily derive the policy functions for consumption and money holdings:

$$
\begin{aligned}
& c=\rho \frac{(1-\beta)(\mu+\rho)}{\mu+\rho(1-\beta)} k \\
& m=\rho \frac{\beta}{\mu+\rho(1-\beta)} k
\end{aligned}
$$


Note that, for a given $k_{t}$, the level of both consumption and money holdings fali with the rate of money supply. The effect on consumption again contrasts with the superneutrality of money in the original Sidrauski model. Note, however, that $k_{t}=k_{0} e_{\gamma \tau}$ and the growth rate depend indirectly on $\mu$ because it affects government

expenditures. So the final effect of a variation in $\mu$ on consumption and money holdings is not unambiguous negative.

\section{The Government Problem}

We can use decision mies (28) and (29) above to study the problem of a government that wants to maximize the welfare of the agents by picking $\lambda$, $\tau$ and $\mu$ optimally. Plugging them in the utility function, after some manipulations we get the following problem for the government:

$$
\begin{aligned}
& \max _{\{\lambda, \mu, \tau)} \int_{0}^{\infty}\{\theta+\ln \rho K+(1-\beta) \ln (\mu+\rho)-\ln (\mu+(1-\beta) \rho)\} e^{-\rho t} \\
& \text { s.t. } \dot{k}=\gamma(\lambda, \mu, \tau) k,
\end{aligned}
$$

where $\theta$ is a constant. The Hamiltonian of this problem is given by:

$$
H(\lambda, \tau, \mu, K)=\theta+\ln \rho K+\beta \ln (\mu+\rho)-\ln (\mu+(1-\beta) \rho)+\vartheta \gamma(\lambda, \mu, \tau) k
$$

It is clear that the maximizing levels of $\tau$ and $\lambda$ of this problem are the same that maximize the growth rate as

$$
\frac{\partial H}{\partial i}=\vartheta \frac{\partial \gamma}{\partial i} K, \text { for } i=\lambda \text { or } \tau
$$

In the above expression we obtain the same result as in section two. When transfers do not affect agent's utility or budget constraint, maximization of growth is always the optimal tax and investment policy. However, the same is not true for the rate of money growth, since the optimal and the maximizing growth rate do not coincide. The first order condition with respect to $\mu$ is

$$
\left(\frac{-1}{\mu+(1-\beta) \rho}+\frac{(1-\beta)}{\mu+\rho}\right)+\vartheta \frac{\partial \gamma}{\partial \mu} K=0
$$

The expression in brackets on the left hand side is unambiguous negative for any so that $\partial \gamma / \partial \mu$ has to be positive for this expression to be zero. The implication is that the optimal growth rate of money is below the growth maximizing rate. The level of consumption and money holdings, given by the policy functions (25) and (26), falis with $\mu$ for a given $\mathrm{K}$, so that the positive growth effect of more inflation taxes trades off with this negative level effect. In other words, a small decrease from the maximum growth level $\mu$ has no first order effect on growth rates but increase consumption and money holding levels, and consequently, consumer welfare.

As a final remark, it is possible to show that when public goods or direct transfer are introduced in this problem, the $\tau$ and $\lambda$ picked by the government are no longer the same as the tax rates and public investment ratios that maximize growth. 
This result reproduces for this more general framework the results we obtained in the previous sections, where maximization of growth rates is only optimal when the government's sole action is to invest in infrastructure.

\section{CONCLUDING REMARKS}

In this note we studied the effect of fiscal and monetary policies in economies where public investment is part of the productive process. The three models presented have in common the same technology, where public investment in infrastructure is a separate argument of the production function.

We used these set-ups to answer some questions about the relationship between public policy, economic growth and welfare. We arrived at some general conclusions:

- Only when there are no transfers, no public goods or no conflict between agents or group of agents is it optimal for the government to maximize growth. $\ln$ general the optimal tax rate is above the rate that maximizes growth, the optimal investment ratio is below one and the optimal inflation rate is below the rate that maximizes growth.

- When the productive role of government is taken into account it is possible to have an interval of tax rates where growth rates increase with taxes. The reason is that the negative impact of extra taxes on the return of private investment is outweighed by the increase in returns due to the rise in public investment. Also, growth rates always increase with the ratio of public investment. These results are presented in other articles in the literature for some of the frameworks we studied.

- With money in the utility function and productive public expenditures, money growth rates affects both the level and growth rate of real variables. We also showed that it is possible for growth rates to increase with inflation for some interval of money creation rates. For this interval, the positive effect on returns caused by the new investments outweigh the distortionary effect of inflation taxes. However, the optimal money creation rate is below the rate that maximizes growth.

Although the frameworks used in the article are highly simplified, our intuition is that most of the results obtained could be achieved in richer environments with more general technologies and information structures.

\section{REFERENCES}

ALESINA,A.andD.RODRIK(1992)"Distribution,PoliticalConflictandEconomicGrowth:aSimple Theor yandSomeEmpírica!Evidence”, inCukierman,A.,Hercowitz,Z.andL.Leiderman(ed.) Political Economy, Growth and Business Cycles, MIT Press, Cambridge,Massachusetts. 
.1994) “Distributive Politics and Economic Growth", Quarterly Journal ofEconomics; 109(2), May, pages 465-90.

ASCHAUER, D. (19 8 9) “Is Public Expenditure Productive? “, Journal of Monetary Economics, 23, March, pp. 177-200.

BARRO, R. J. (1990) “Government Spending in a Simpie Model of Endogenous Growth”, Journal of Political Economy, 98, pp. S103-25

BARRO, R. J., and X. SALA-I-MARTIN (1992) "Public Finance in Models of Economic Growth", Review of Economic Studies, vol. 59 (201), pp. 645-662. . (1995) "Economic Growth", McGraw-Hill, New York.

CAVAlCANTI FERREIRA, P. (1993), "Essays on Public Expenditure and Economic Growth”, Manu script, Unpublished Ph.D. Dissertation, University of Pennsylvania.

NADIRI, M. I. and T. P. MANUNEAS (1992) "The Effects of Public Infrastructure and R\&D Capital on the Cost Structure and Performance of US Manufacturing Industries”, Manuscript, New York University.

REBELO, S. (1991) "Long Run Policy Analysis and Long Run Growth", Journal of Political Economy, 99, pp. 500-21.

ROUBINI, N. and X. SALA-I-MARTIN (1995) “A Growth Model of Inflation, Tax Evasion and Financial Repression”, Journal of Monetary Economy, 35, pp. 275-301.

SIDRAUSKI, M. (1967) "Rational Choice and Patterns of Growth in a Monetary Economy", American Economic Review, 57, pp. 534-44. 